\title{
Vulnerability of Farmers to Crop Farming Risks in Ethiopia: An Integrated Vulnerability Analysis Approach Using Social-Ecological System Framework
}

\author{
Chalchisa Fana $^{1}$, Jama Haji ${ }^{2}$, Moti Jaleta ${ }^{3}$, Alelign Ademe ${ }^{4} \&$ Girma Gebresenbet $^{5}$ \\ ${ }^{1}$ Ambo University, College of Agricultural and Veterinary Science, Ambo, Ethiopia \\ ${ }^{2}$ Haramaya University, College of Agriculture and Environmental Science, Haramaya, Ethiopia \\ ${ }^{3}$ International Maize and Wheat Improvement Center (CIMMYT), Addis Ababa, Ethiopia \\ ${ }^{4}$ Haramaya University, College of Agriculture and Environmental Science, Haramaya, Ethiopia \\ ${ }^{5}$ Swedish University of Agricultural Sciences, Department of Energy and Technology, Uppsala, Sweden \\ Correspondence: Chalchisa Fana, Ambo University, College of Agricultural and Veterinary Science, Ambo, \\ Ethiopia. E-mail: hinsarmufana@gmail.com
}

Received: November 6, 2020 Accepted: March 11, 2021 Online Published: May 27, 2021

doi:10.5539/sar.v10n3p25 URL: https://doi.org/10.5539/sar.v10n3p25

\begin{abstract}
Crop production under a smallholder system is challenged by several (a)biotic risks those resulted in livelihood insecurity. This study assesses farmers' perceived vulnerability level to the crop farming risks and identifies its determinants using an integrated vulnerability analysis approach. Survey data collected from 393 sample households in West Shewa Zone, Ethiopia, were analyzed using PCA and ordered probit regression. Results indicate that 13 percent of the sampled households are highly vulnerable, 73.5 percent are moderately vulnerable and 13.5 percent are less vulnerable where 77 percent of the highly vulnerable groups faced more than 3 months lean season and 72 percent of the less vulnerable groups faced less than 3 months of lean season. Moreover, farming experience and education level of household head, livestock owned, farm size, on-farm diversification, access to credit, small scale irrigation, off-farming income, extension contact, and social capital are significantly affecting the perceived vulnerability level. These calls for need-based government and/or non-government intervention plans focusing on improving rural infrastructure and facilities and devising an effective and responsive institutional setup for enhancing the responsive capacities of smallholder farmers in the short-run and minimizing the likelihood of exposure and sensitivity in the long-run.
\end{abstract}

Keywords: integrated vulnerability, exposure, susceptibility, response capacities, perceived vulnerability index

\section{Introduction}

Smallholder farmers in Ethiopia are engaged in mixed crop-livestock farming systems for their livelihoods (Yitayal and Adam, 2017). Ensuring household consumptions and generating income are the key aspirations guiding farmers' decisions on resource use and allocation in crop production (Kahan, 2008 and Wallace and Moss, 2002). Because of the underlying complexities, uncertainties, and dynamics landscape of the farming system (Feola and Binder, 2010), crop producers might not realize the aspired states certainly. Empirical evidence indicates that production, marketing, institutional, human, and financial risks are the pronounced classes of multitude risks underlying the crop farming system (Asravor, 2019; Bard and Barry, 2001; Belaineh and Drake, 2005; Duong et al., 2019; Harvey et al., 2014; Harwood et al., 1999; Helamo, 2018 and Singh, 2018). These multitudes of risks would induce dual adverse impacts on the livelihood outcome: a loss of farm income on the one hand and a diversion of scarce resources, time, and efforts from other livelihood strategies to combat the adverse impact on the other hand (Larcher et al., 2016 and Shikuku et al., 2017).

The aggregated adverse impacts of multitude risks affect the income distribution and ultimately the livelihood security of smallholder farmers (Williams et al., 2018). The uncertainties and complexities underlying the crop farming system (Feola and Binder, 2010) on the one hand; and smallholder farmers' limitations to anticipate and integrate the likely uncertainties and complexities into their production decisions, on the other hand, overplays the level of livelihood insecurity (Moschini and Hennessy, 1999). The nature and extent of adverse impacts 
would be predicted from the outcome of the crop production risk chain (World Bank, 2013) where the risk chain outcome is the function of multi-pressures multi-vulnerability pathways of the farming system (Feola $e t$ al., 2015). Dropping below the socially accepted threshold of well-being is the major negative impact of multi-pressure multi-vulnerability pathways (Zarafshani et al., 2012) whereas the socially accepted threshold of well-being could be predicted from the household's consumption level (Christiaensen and Subbarao, 2004). Besides, the threshold of well-being as a function of the farm household's consumption level is correlated with the lean season. Thus, the length of the lean season can represent the locus of farm households in the continuum of vulnerability pathways.

The social-ecological system model provided a noble insight for understanding the underlying and ultimate outcomes of crop farming system risk chains (Feola et al., 2015 and Walker et al., 2006). Moreover, the social-ecological system model captured the context specificity and dynamic phenomenon of vulnerability on the one hand and the series of actions enacted by farmers shaped by the learning and reorganizing process on the other hand (Feola et al., 2015 and Walker et al., 2006). Besides, the learning and reorganizing process of farmers complemented by the absolute and relative amount of livelihood resources (Walker et al., 2006). Hence, the social-ecological system provided the integrative insight to analyze smallholder farmers' vulnerability as the function of multi-stressors causal chains and multi-vulnerability pathways.

However, despite smallholder farmers of the developing world are exposed to multi-stressors (Feola et al., 2015; Singh et al., 2018 and Singh and Nair, 2014), most scholars have assessed the vulnerability of small-scale farmers in their cases focusing on climate change impacts as a single stressor (Fang et al., 2016; Gbetibouo et al., 2010; Ginkel et al., 2013; Hahn et al., 2009; Israel and Belay, 2019; Jamshidi et al., 2019; Opiyo et al., 2014; Pandey et al., 2017; Paulos and Belay, 2018; Sattar et al., 2017; Zarafshani et al., 2012 and Zenebe et al., 2016). In the same vein, despite the context-specific and dynamic phenomenon of vulnerability, most of the current empirical works overlook the dynamic and context-specific features of vulnerability (Eitzinger et al., 2018 and Singh and Nair, 2014). On the other hand, empirical evidences indicated that the context-specific and dynamic phenomenon of vulnerability will be more understandable through studying farmers' metal model (Eitzinger et al., 2018; Singh and Nair, 2014 and Walker et al., 2006).

On top of this, because of fragile livelihood resources (degraded natural resources, poor physical resources, unskilled human resources, weak financial resources, and fragile social capital) (Bezuayehu et al., 2002; Dubale, 2001; Gebreegziabher et al., 2016 and Saguye, 2017), the aggregated adverse impacts of crop farming risks is substantial in Ethiopia. Thought agreeable in the study area too. This justifies the relevance of dealing with smallholder farmers' vulnerability in the study area using an integrative insight. In the same vein, to the level of our understanding, leave alone the study area, empirical knowledge of the glob confirmed that the former empirical works on farmers' vulnerability studies are noising modeling and metrics limitation. Thus, this study was initiated (1) to analyze perceived vulnerability of smallholder farmers to crop farming risks; and (2) to identify determinants of smallholder farmers' perceived vulnerability level in the study area using an integrative vulnerability analysis framework and semi-quantitative attitudinal scale metrics.

The findings of this study shed light on the perceived vulnerability level and the determinants of smallholder farmers' perceived vulnerability level in the crop farming system of the study area. In general, the study generated information on the perceived vulnerability constituents: perceived exposure factors, perceived sensitivity factors, and perceived response capacities factors. Moreover, the study identified determinants of smallholder farmers' responsive capacities. The generated information might be used by the government or non-government organizations for an effective need-based intervention plan to support smallholder farmers. Finally, the nobility statement of the paper is that the study introduced indicators of the perceived vulnerability and sketched the conceptual framework of smallholder farmers' vulnerability to the adverse impacts of risks in the study area.

\section{Research Methodology}

\subsection{Conceptual Framework of the Study}

As long as vulnerability is a context-specific and dynamic phenomenon that depends on both social and ecological process (Fang et al., 2016; Roxana et al., 2012 and Sattar et al., 2017), the social-ecological system model is more efficient to describe the vulnerability of farmers (Feola et al., 2015; Feola and Binder, 2010 and Walker et al., 2006). Empirical knowledge categorized the incumbent vulnerability analysis framework into biophysical vulnerability, social vulnerability, and integrated vulnerability analysis (Adger, 1995; Adger, 2006; Brien et al., 2004; Murphy et al., 2015 and Olusola, 2014). However, the limitations of the aforementioned framework are pronounced in the literature. The social vulnerability framework overlooks the likely impact of a 
different environmental attribute on a different level of vulnerability whereas the biophysical vulnerability framework overlooks the adaptive capacity of individuals or groups (Adger, 2006 and Olusola, 2014). Even though the integrative vulnerability framework corrected the limitation of biophysical and social vulnerability analysis, a lack of a standard method for combining the biophysical and socioeconomic indicators counted as the limitation of the integrative framework (Olusola, 2014).

Furthermore, empirical knowledge categorized the metrics of vulnerability assessment into vulnerability variables and indicator approach (Gbetibouo and Ringler, 2009 and Olusola, 2014). Similarly, the vulnerability variables assessment approach categorized into vulnerability as exposure to poverty (VEP), vulnerability as exposure to low expected utility (VEU), and vulnerability as exposure to uninsured risks (VER) (Olusola, 2014; Oni, 2008 and Yitayal and Adam, 2017). All the three vulnerability variable metrics approaches shared common characteristics in that they measure loss in well-being induced by shocks using the measure of the probability of well-being indicators falling below the reference benchmark for welfare indicators (Olusola, 2014). However, the insufficiency to fully capture all the dimensions of vulnerability into a single measure counted as the limitation of the vulnerability variable metrics approach (Gbetibouo and Ringler, 2009). In the indicator method, the researchers select some of the indicators from the whole set of potential indicators and then systematically combine the selected indicators to estimate the level of vulnerability. In this method, the vulnerability index was computed applying equal weight or expert judged weight or fuzzy logic weight for each indicator and statistical methods like principal component analysis (PCA).

In general, overlooking the multi-exposure causal chain of vulnerability, dynamic and context-specific phenomenon of vulnerability, insufficiency of a single metrics to capture all dimension of vulnerability, and lack of standard weight to combine indicators are documented as the limitations of the former vulnerability empirical works (Eitzinger et al., 2018; Feola et al., 2015; Feola and Binder, 2010; Singh et al., 2018; Singh and Nair, 2014 and Walker et al., 2006). This study is differentiated from most of the former works in modeling, methodological approach, and metrics of the farming system vulnerability. The study applied the social-ecological system model, attitudinal scale metrics, and PCA methodology to analyze smallholder crop producers' vulnerability in the study area. Since the context-specific and dynamic phenomenon of vulnerability will be more understandable from the farmers' perceptions and experiences (Adger, 2006; Eitzinger et al., 2018; Singh and Nair, 2014 and Walker et al., 2006), this study applied attitudinal scale metrics to elicit smallholder farmers' vulnerability components (exposure, sensitivity, and adaptive capacity) using indicators from their perception and experiences.

As the adverse impacts of multitude risks induced a declined well-being, the exposure factors capture the likelihood to face a declined well-being inducing factors where the degree of exposure predicts the level of perceived vulnerability. Thus, the operational definition of exposure in this study is the likelihood of a given farm household to face a declined well-being inducing factors. Perceived exposure was measured using a proxy indicators of exposure on a Likert scale with five response options ranged from (1) very low impact to (5) very high impact based on the respondents' perception.

Sensitivity/susceptibility describes the propensity of the crop farming system to suffer harm in the face of multitude risks. The nature of subsistence farming and fragility in access to farm livelihood resources exacerbate the level of aggregated adverse impacts of risks. Empirical evidences proved that in the face of exposure to multitude risks, households with susceptible livelihood activities are more vulnerable than the non-susceptible ones. The operational definition of perceived susceptibility in this study is smallholder farming systems' propensity to realize a decline in well-being. The level of perceived susceptibility measured using the agreement level on the proxy indicators of susceptibility components on a Likert scale with five response options ranged from (1) strongly disagree to (5) strongly agree based on the respondents' perception.

The level of adaptive/responsive capacities would be determined by the level of access and ability to mobilize the resources to avoid a decline in well-being below the socially accepted threshold. The operational definition of perceived responsive capacities in this study is the level of access and ability of smallholder farmers in mobilizing resources to prevent or resist or cope with a decline in well-being. Moreover, empirical evidence proved that farming households with limited access and ability in mobilizing resources are more vulnerable than those with better access and ability. Perceived responsive capacities was measured using the level of agreement on the proxy indicators of access and ability components on a Likert scale with five response options ranged from (1) strongly disagree to (5) strongly agree based on the respondents' perception.

Moreover, the economically vulnerable condition is represented as the net effect of responsive capacities, sensitivity, and exposures. In the subsistence farming system, the negative impacts of multi-pressure 
multi-vulnerability pathways can lead to a long lean season where lean season represents the time when farm households find difficult to meet the consumption need. Thus, the length of the lean season can be measured as the number of months in which farm households faced difficulty to meet the consumption need smoothly.

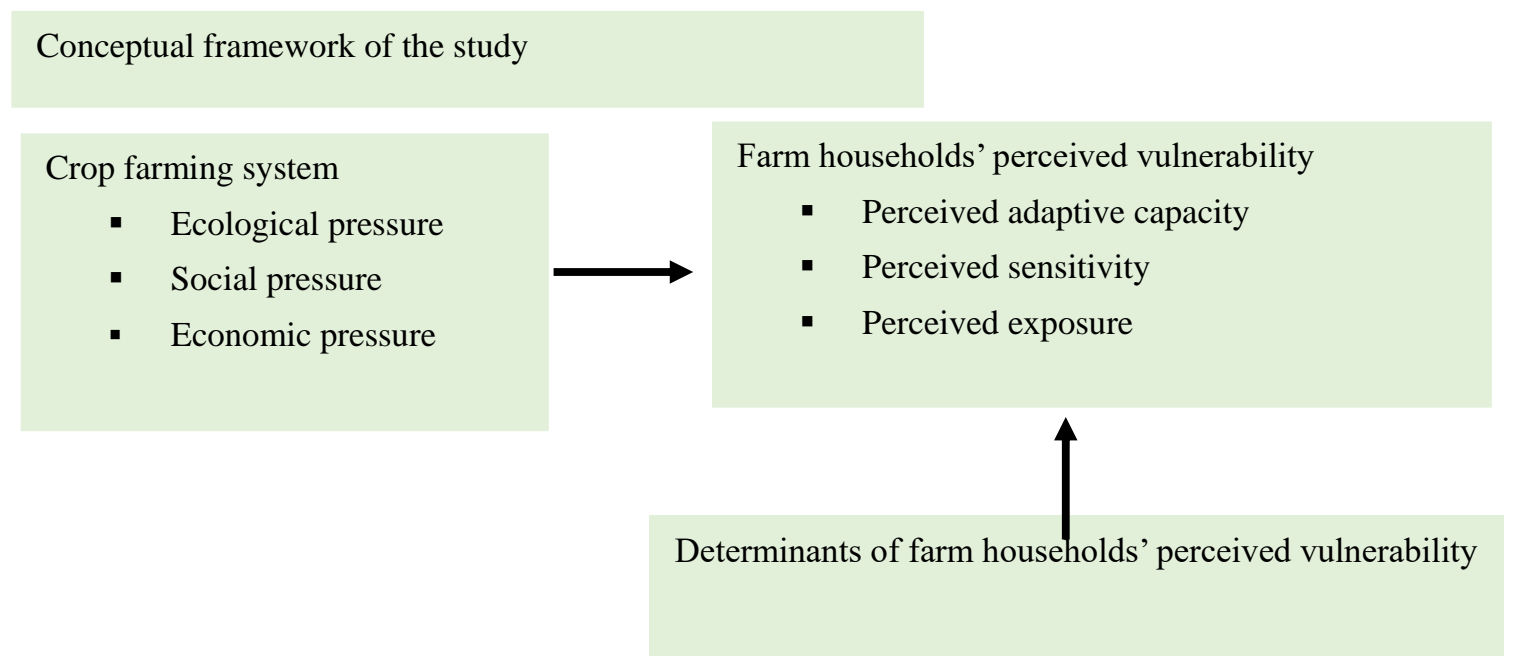

\subsection{The Study Area}

The study was conducted in the West Shewa zone located at $8^{\circ} 17^{-} 8^{\circ} 57^{\prime} \mathrm{N}$ latitude and $37^{\circ} 08-38^{\circ} 07^{\prime} \mathrm{E}$ longitudes with an altitude ranging from 1380-3300 m.a.s.l consisting of lowland, midland, and highland agroecologies. The annual average rainfall was $1115 \mathrm{~mm}$. The mean maximum and minimum temperature of the zone is $11.7^{\circ} \mathrm{C}$ and $25.4^{\circ} \mathrm{C}$, respectively. There are 22 woredas and 529 rural kebeles in this zone. Moreover, the zone has a total population of 428,689 rural households with an average of 4.80 persons per household and 611, 783.7 ha arable land. The livelihood strategy of the zone is mainly dominated by subsistence mixed farming systems (crop cultivation and livestock production). The crops produced in the zone are broadly grouped into field crops and horticultural crops. Maize, sorghum, teff, wheat, and burly are the major staple cereal crops; faba bean, haricot bean, field pea, grass pea, and chickpea are the major pulse crops; niger seed and lentil seed are the major oil crops; and tomatoes, potatoes, onions, garlic, cabbages, and beetroot are the major vegetable crops produced in the zone. The annual productivity of the field crops is $25.21 \mathrm{qt} / \mathrm{ha}$ crops equivalent yield. (West Shawa Zone, Agriculture, and Rural Development Office, 2019). 


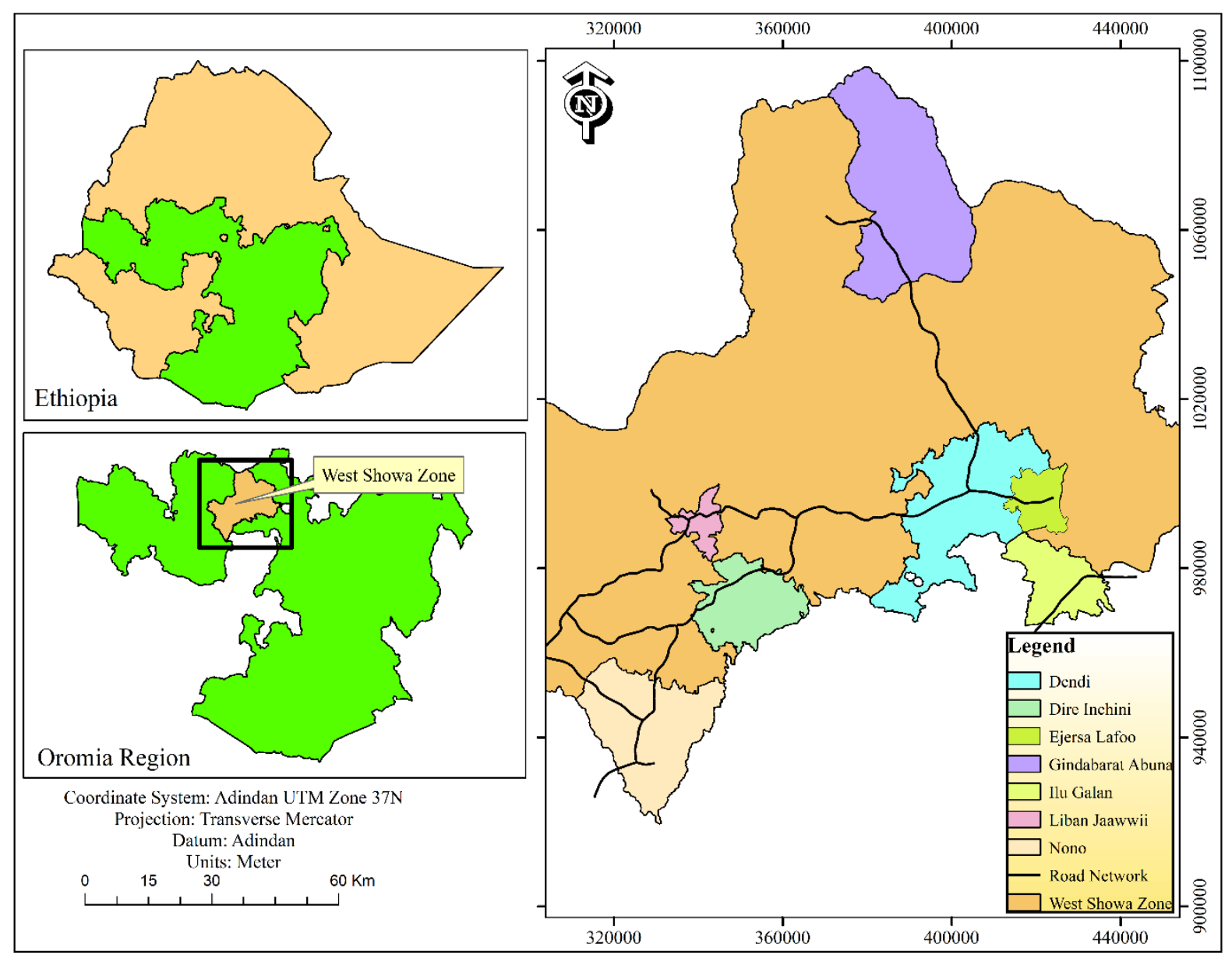

Figure 1. Map of the study area

\subsection{Data Types, Sources and Collection Techniques}

In this study, both qualitative and quantitative types of data were considered. The qualitative types of data refers to the research subjects view, believes, perceptions and expressions on the issues at hand. Sources of the qualitative data are the purposively selected expert groups and focused groups. Such types of data were accessed from the mental constructs of the study units during the group discussions using unstructured survey tools such as guiding questions and checklists referring the indicators of vulnerability components the crop farming system in the study area. Similarly, quantitative types of data refers to the measureable or quantifiable data accessed from responses of the research subjects. In this study, both primary and secondary sources of data were consulted to access the quantitative data. The primary sources of data is the randomly selected sample farm households of the study area whereas the secondary sources of data includes annual reports, manuals and empirical literatures related to the study area or elsewhere with similar contexts. Such types of data were collected using content analysis of the secondary sources and semi-structured questionnaire for the sampled farm households.

All the survey tools for the sample farm households were derived from results of the qualitative research and content analysis of the empirical literatures related to the topic. Moreover, the survey tools include the socio-economic, psycho-cognitive and bio-physical factors of the crop farming system and the proxy indicators of the farm households' perceived vulnerability components. To accomplish the interview schedule, 12 extension agents, one per kebele were recruited and trained for one day to be familiarized with objectives of the study and survey tools; and the mechanism of interview schedule. The survey tools were converted into Afan Oromo to ensure the easily understandability of the tools by the recruited extension agents and the sampled farm households.

\subsection{Sampling Method and Sample Size}

The study used both purposive and random sampling strategy to obtain representative sample size. In qualitative 
research, purposive sampling strategy was applied to conduct seven groups of expert group discussion (EGD) and five groups of focus group discussion (FGD). One EGD and one FGD were held in each sampled woreda. The number of FGD was determined using data saturation point (DSP). In quantitative research phase, stratified multistage random sampling strategy was employed to obtain representative sample of farm households. At first stage, West Shoa zone was stratified into highland, midland and lowland agro ecologies. There are three woredas in the highland, 9 in midland and 10 in lowland agro-ecologies. Following this, seven woredas: one from high land, three from midland and three from lowland agro-ecologies were proportionally and randomly selected. In the second stage, twelve (12) kebeles: two from highland, four from midland and six from lowland agro-ecologies were proportionally and randomly selected. The number of sample kebeles is $10 \%$ of the total kebels in smapled woreda. In third stages, representative farm households were randomly selected from the sampled kebeles using probability proportional to the sample size (PPSS) approach.

The sample size of this study was determined using Cochran (1963) sample size determination formula. Empirical evidences revealed that to determine the appropriate sample size, the three sample size criteria, namely, the level of precision, the level of confidence and the degree of variability in the attribute being measured will need to be specified. The level of precision refers the range in which the true value of the population to be estimated and is often expressed in percentage point (e.g. most of the empirical work used +/-5 percent). Level of confidence refers percentage of the samples from the total samples that have true population value within the specified range of precision (e.g. most of the empirical works used 95 percent). The degree of variability refers the distribution of attributes in the population and most of the time 0.5 is used as degree of variability unless specified and 0.5 refers the maximum variability. Thus, considering this, Cochran (1963), derived the sample size determination formula for the large size (infinite) population as

$$
\mathrm{n}_{\mathrm{o}}=\frac{\mathrm{z}^{2} \mathrm{pq}}{\mathrm{e}^{2}}
$$

Where $n_{0}$ refers to the representative sample for proportions, $z^{2}$ refers to the abscissa of the level of confidence, $p$ refers to the degree of variability, q refers to $1-p$, and e refers to the desired level of precision. The value of $z$ is found in statistical table which contain the area under the normal bell-shaped curve.

$$
\mathrm{n}_{\mathrm{o}}=\frac{\mathrm{Z}^{2} \mathrm{pq}}{\mathrm{e}^{2}}=\frac{(1.96)^{2}(0.5)(0.5)}{(.05)^{2}}=385
$$

Thus, from this equation, a representative sample of 385 were determined. Moreover, for any finite population size, this equation (formula) can be adjusted or corrected as

$$
\mathrm{n}=\frac{\mathrm{N}\left(\mathrm{n}_{\mathrm{o}}\right)}{\mathrm{N}+\left(\mathrm{n}_{\mathrm{o}}-1\right)}
$$

Where $\mathrm{n}$ is the corrected sample size, and $\mathrm{N}$ is the target population size. Given that the targeted population of this study is 86,847 farm households, the sample size for this study is determined as

$$
\mathrm{n}=\frac{\mathrm{N}\left(\mathrm{n}_{\mathrm{o}}\right)}{\mathrm{N}+\left(\mathrm{n}_{\mathrm{o}}-1\right)}=\frac{86,847(385)}{86,847+384}=\frac{33,436,095}{87,231}=383.31 \cong 383
$$

Therefore, the representative sample size for this study was 383 farm households with $5 \%$ of contingence allowance.

\subsection{Methods of Data Analysis}

The survey data were analyzed using the congruent reports of the rapporteurs to construct the narrated scenarios in the qualitative study phase and applying descriptive statistics and econometric models in the quantitative study phase. Ahead of the econometric analysis, scale reliability test, and validity test were employed to ensure the internal consistency of the indicators.

\section{Econometric Analysis of Farm Households' Perceived Vulnerability}

Farm households' perceived vulnerability was econometrically analyzed using the PCA methodology and the ordered probit regression. The PCA methodology was used to measure the farm households' perceived vulnerability as the net effect of adaptive capacity factors, sensitivity factors and exposure factors whereas ordered probit regression model was used to identify the determinants of farm households' perceived vulnerability level.

\section{Measurement of farm households' perceived vulnerability}

The PCA methodology was applied to compute the composite index of farm households' perceived vulnerability 
as a net effect of adaptive capacity factors, sensitivity factors and exposure factors. Following the IPCC working definitions of vulnerability as a net effect of adaptive capacity factors, sensitivity factors and exposure factors and the empirical works of Glwadys et al. (2010), Jamshidi et al. (2019), Opiyo et al. (2014) and Zenebe et al., (2016), farm households' perceived vulnerability as a net effect of perceived vulnerability components is specified as:

$$
\text { Vulnerbility }=(\text { Adaptive Capacity })-(\text { Susceptibility }+ \text { Exposure })
$$

This implies when farm households' perceived adaptive capacity exceeds that of perceived sensitivity and perceived exposure, a given farm household is less vulnerable to the adverse impacts of crop farming risks and vice versa. Since farm households' perceived adaptive capacity, perceived sensitivity and perceived exposure are consisting multi-indicators or variables, the PCA methodology is used to generate standardized weight of multi-indicators and compute composite index of perceived vulnerability using PCA1. The PCA1 specification for the composite index of farm households' perceived vulnerability is:

$$
V_{1}=\left(A_{1} X_{1 j}+A_{2} X_{2 j}+\ldots+A_{n} X_{n j}\right)-\left(A_{n+1} Y_{1 j}+A_{n+2} Y_{2 j}+\ldots+A_{n+n} Y_{n j}\right)
$$

Where $V_{1}$ refers to composite index of farm households' perceived vulnerability, $X_{S}$, refers to elements of perceived adaptive capacity, and $Y_{S}$, refers to elements of perceived sensitivity and perceived exposure. The value of $\mathrm{X}$ and $\mathrm{Y}$ is obtained by normalization using $X_{-} 1 j=\left(\left(X_{-} 1 j-X_{-} 1^{\wedge} *\right)\right) /\left(S_{-} 1^{\wedge} *\right)$, where $X_{1}^{*}$ is the mean of $X_{1 j}$ across the sampled households, and $S_{1}^{*}$ is its standard deviation. This implies PCA1 is the linear index of all the variables that captures the largest amount of information common to all the variables. The whole matrix of $X_{1 j}$ appears as follows:

$$
X_{i j} / Y_{i j}=\left\{\begin{array}{c}
\left(X_{11}+X_{12}+\ldots+X_{1 n}\right)-\left(Y_{11}+Y_{12}+\ldots+Y_{1 n}\right) \\
\cdot \\
\vdots \\
\left(X_{m 1}+X_{m 2}+\ldots+X_{m n}\right)-\left(Y_{m 1}+Y_{m 2}+\ldots+Y_{m n}\right.
\end{array}\right\}
$$

The $i$ and $j$ in the above notation implies the number of rows (in this case sampled households) and the number of columns (in this case variables of adaptive capacity, sensitivity and exposure) respectively. Finally, the composite index of farm households' perceived vulnerability as a net effect of perceived vulnerability components is obtained using

$$
V_{i}=\left[\begin{array}{c}
A_{1} \\
A_{2} \\
\cdot \\
\cdot \\
\cdot \\
\cdot \\
A_{n+n}
\end{array}\right] X\left[\begin{array}{c}
\left(X_{11}+X_{12}+\ldots+X_{1 n}\right)-\left(Y_{11}+Y_{12}+\ldots+Y_{1 n}\right) \\
\cdot \\
\left(X_{m 1}+X_{m 2}+\ldots+X_{m n}\right)-\left(Y_{m 1}+Y_{m 2}+\ldots+Y_{m n}\right)
\end{array}\right]
$$

$A_{S}$, refers to the first loading score of each indicators or variables of perceived vulnerability components computed by PCA1. In calculating the direction of relationship among the vulnerability components (i.e., their sign), a negative value was assigned to both exposure and sensitivity. This implies high perception of exposure to crop farming risks, more perception of sensitivity to the negative impacts of risks, assuming constant adaptive capacity. The higher net value indicates lesser vulnerability and vice versa. In this study, indicators of the farm households' adaptive capacity are ability to anticipate crop farming risk factors, adequate annual farming income, adequate farm reservoir, access of non-farming income and access of external financial source. In the same way, indicators of farming system sensitivity are limited size of farm land, exhaustive farming system, subsistence farming, conservative farming system and lack institutional support while indicators of exposures includes climate variability, degradation of farmland fertility, low access of improved inputs, incidence of crop diseases and pests, price instability and seasonal deficit of farming labor.

\section{Determinants of farm households' perceived vulnerability}

Ordered probit regression model was used to identify the determinants of farm households' perceived vulnerability level. In this analysis, the level of perceived vulnerability was classified into three categories: highly vulnerable households whose vulnerability index is $\leq$ mean - standard deviation; moderately vulnerable households whose vulnerability index lies between mean \pm standard deviation; and less vulnerable households 
whose vulnerability index is $\geq$ mean + standard deviation. Highly vulnerable class refers to farm households who are sensitive and exposed to the crop farming risks and do not have adequate adaptive capacity without external support. Moderately vulnerable class refers to farm households who need urgent, but temporary external assistance to recover from the negative impacts of crop farming risks. Less vulnerable class refers to farm households who are in a vulnerable situation but still able to cope without external support. Thus, farm households' perceived vulnerability level in this measurement involved ordered outcomes referring the net effect perceived vulnerability components. Moreover, the adverse impacts of crop farming risks is expected to affect farm households differentially based on their adaptive capacity.

Following Green (1997) cited in Opiyo et al. (2014) the reduced form ordered probit regression model to identify determinants of farm households' perceived vulnerability level is specified as:

$$
Y_{j}^{*}=X_{i j}^{1} \beta+U_{1 j}
$$

$Y_{j}^{*}$ refers to the latent variable of farm households' perceived vulnerability level, referring the composite index of farm households' perceived vulnerability, $\mathrm{X}_{\mathrm{ij}}$ refers to explanatory variables of farm households' perceived vulnerability, $\beta$ refers to parameters to be estimated, and $U_{1 j}$ refers to the disturbance term or residual of the model. Moreover, structural form of the ordered probit regression model was specified as:

$$
\begin{gathered}
Y_{j}=1 \text { if } Y_{j}^{*} \leq 1 \\
Y_{j}=2 \text { if } 1<Y_{j}^{*} \leq 2 \\
Y_{j}=3 \text { if } 2<Y_{j}^{*} \leq 3
\end{gathered}
$$

$Y_{j}$ refers to farm households' perceived vulnerability level, $Y_{j}=1$ if $Y_{j}^{*}$ lies in high vulnerability classes; $Y_{j}=2$ if $Y_{j}^{*}$ lies in moderate vulnerability class; and $Y_{j}=3$ if $Y_{j}^{*}$ lies in less vulnerability class. Both of the farm households' perceived vulnerability measurement model and the determinants of perceived vulnerability estimation model were run using STATA version 14 software.

\section{Result and Discussion}

\subsection{Descriptive Statistics of Perceived Vulnerability Level}

The composite index of the farm households' perceived vulnerability computed by the PCA methodology is ranged in -4.567 to 4.644 with a mean $-6.53 \mathrm{E}^{-09}$ and standard deviation of 2.323 . We estimated the individual households' vulnerability level and classes using mean +/- standard deviation. Smallholder farmers with composite index ranged below -2.32 are classified as highly vulnerable, between -2.32 and 2.32 are classified as moderately vulnerable, and ranged above 2.32 are classified as less vulnerable. As reported in Table 1, 12.98 percent of the sampled households are highly vulnerable, 73.54 percent are moderately vulnerable and 13.49 percent are less vulnerable while the largest proportion of them (73.54\%) are moderately vulnerable. On the other hand, vulnerable farm households are exposed to livelihood insecurity. In this study, the farm household livelihood insecurity is accessed using the length of lean season a given farm household is used to face. As reported in Table 8, more than 77 percent of the highly vulnerable groups of farm households are faced more than 3 months of lean season whereas about 72 percent of the less vulnerable groups are faced less than 3 months of lean season. This implies that highly vulnerable groups are faced longer lean season than less vulnerable groups.

Table 1. Descriptive statistics of farm households' perceived vulnerability level

\begin{tabular}{llll}
\hline \multicolumn{4}{l}{ Perceived vulnerability level } \\
\hline Lean season in month & $\begin{array}{l}\text { Highly vulnerable } \\
\text { frequency }(\%)\end{array}$ & $\begin{array}{l}\text { Moderately vulnerable } \\
\text { frequency }(\%)\end{array}$ & $\begin{array}{l}\text { Less vulnerable } \\
\text { frequency }(\%)\end{array}$ \\
\hline 0 & $0(0.00)$ & $1(0.35)$ & $0(0.00)$ \\
1 & $1(1.96)$ & $2(0.69)$ & $0(0.00)$ \\
2 & $4(7.84)$ & $53(18.34)$ & $38(\mathbf{7 1 . 7 0})$ \\
3 & $6(11.76)$ & $122(\mathbf{4 2 . 2 1})$ & $8(15.09)$ \\
4 & $5(9.80)$ & $88(30.45)$ & $6(11.32)$ \\
5 & $33(\mathbf{6 4 . 7 1})$ & $22(7.61)$ & $1(1.89)$ \\
6 & $2(3.92)$ & $1(0.35)$ & $0(0.00)$ \\
$\mathrm{n}=393$ & $51(100.00)$ & $289(100.00)$ & $53(100.00)$ \\
\hline
\end{tabular}

Note: Numbers in parenthesis are column percentages

Source: Own survey data, 2018/19 


\subsection{Descriptive Statistics of Dummy Variables by Perceived Vulnerability Level}

As shown in Table 2, out of 27 female headed sample farm households, 12 (44.44) are highly vulnerable, 11 $(40.74 \%)$ are moderately vulnerable and $4(14.81 \%)$ are less vulnerable to crop farming risks. The percentage difference of female-headed farm households among the highly vulnerable, moderately vulnerable and less vulnerable groups is statistically significant at $1 \%$ probability level. Out of 248 sample farm households of less access of on-farm diversification, $44(17.74 \%)$ are highly vulnerable, 190 (76.61\%) are moderately vulnerable and $14(5.65 \%)$ are less vulnerable to the crop farming risks. The percentage difference of the less access of on-farm diversification among farm households of highly vulnerable, moderately vulnerable and less vulnerable groups is statistically significant at $1 \%$ probability level. Out of 331 farm households of less access of credit, 48 (14.5\%) are highly vulnerable, $256(77.34 \%)$ are moderately vulnerable and $27(8.16 \%)$ are less vulnerable to the crop farming risks. The percentage difference of the less access of credit among farm households of highly vulnerable, moderately vulnerable and less vulnerable groups is statistically significant at $1 \%$ probability level. Out of 356 non-irrigation user farm households, 48 (13.48\%) are highly vulnerable, 277 (77.81\%) are moderately vulnerable and $31(8.71 \%)$ are less vulnerable to crop the farming risks. The percentage difference of the non-irrigation users among farm households of highly vulnerable, moderately vulnerable and less vulnerable groups is statistically significant at $1 \%$ probability level. Out of 246 sample farm households of less access of non-farming income opportunities, $39(15.85 \%)$ are highly vulnerable, $193(78.46 \%)$ are moderately vulnerable and $14(5.69 \%)$ are less vulnerable to the crop farming risks. The percentage difference of the less access of non-farming income opportunities among farm households of highly vulnerable, moderately vulnerable and less vulnerable groups is statistically significant at $1 \%$ probability level. Out of 53 farm households of less trust of social groups, $20(37.74 \%)$ are highly vulnerable, 33 (62.26\%) are moderately vulnerable and none of them are less vulnerable to the crop farming risks. The percentage difference of the less trust in social groups among farm households of highly vulnerable, moderately vulnerable and less vulnerable groups is statistically significant at $1 \%$ probability level.

Table 2. Descriptive statistics of dummy variable by perceived vulnerability level

\begin{tabular}{lllllllll}
\hline & & \multicolumn{2}{l}{$\begin{array}{l}\text { Highly } \\
\text { vulnerable }(\mathrm{n}=51)\end{array}$} & \multicolumn{2}{l}{$\begin{array}{l}\text { Moderately } \\
\text { vulnerable }(\mathrm{n}=289)\end{array}$} & \multicolumn{4}{l}{$\begin{array}{l}\text { Less vulnerable } \\
(\mathrm{n}=53)\end{array}$} \\
\hline Dummy variables & Category & $\mathrm{N}$ & $\%$ & $\mathrm{~N}$ & $\%$ & $\mathrm{~N}$ & $\%$ & $\chi^{2}-$ vlaue \\
\hline Sex of household & Female & 12 & 44.44 & 11 & 40.74 & 4 & 14.81 & $22.97^{* * * *}$ \\
On-farm diversification & Less & 44 & 17.74 & 190 & 76.61 & 14 & 5.65 & $43.27^{* * *}$ \\
Credit access & Less & 48 & 14.5 & 256 & 77.34 & 27 & 8.16 & $52.07^{* * *}$ \\
Irrigation & Non-user & 48 & 13.48 & 277 & 77.81 & 31 & 8.71 & $71.20^{* * *}$ \\
Non-farming income & Less & 39 & 15.85 & 193 & 78.46 & 14 & 5.69 & $35.99^{* * *}$ \\
Social groups & Less & 20 & 37.74 & 33 & 62.26 & 0 & 0 & $39.25^{* * *}$ \\
\hline
\end{tabular}

Note: *** refers $1 \%$ significance level

Source: Own survey data, 2018/19

\subsection{Descriptive Statistics of Continuous Variable by Perceived Vulnerability Level}

As reported in Table 3, the mean of sample farm household heads' farming experience in highly vulnerable, moderately vulnerable and less vulnerable condition is $22.08,23.59$ and 26.17 years with a standard deviation $10.65,9.80$ and 10.23 respectively. The mean difference of farm household heads' farming experience among the highly vulnerable, moderately vulnerable and less vulnerable groups is statistically insignificant. The mean education level of sample farm household heads in highly vulnerable, moderately vulnerable and less vulnerable groups are 1.22, 3.12 and 5.72 years of schooling with a standard deviations $2.29,3.62$ and 3.84 respectively. The mean difference in education level of household heads among the highly vulnerable, moderately vulnerable and less vulnerable groups is statistically significant at $1 \%$ probability level. The mean size of sample households in highly vulnerable, moderately vulnerable and less vulnerable groups are 6.84, 6.82 and 7.42 members with standard deviations $2.85,2.51$ and 2.90 respectively. The mean difference in size of households between the highly vulnerable, moderately vulnerable and less vulnerable groups is statistically insignificant.

Similarly, the mean size of livestock owned by sample farm households in highly vulnerable, moderately vulnerable and less vulnerable groups are 4.28, 7.09 and 10.86 TLU with standard deviations 2.02, 2.25 and 3.21 respectively. The mean difference of farm households' livestock endowment among the highly vulnerable, moderately vulnerable and less vulnerable groups is statistically significant at $1 \%$ probability level. The mean 
size of farmland owned by sample farm households in highly vulnerable, moderately vulnerable and less vulnerable groups are 1.04, 1.95 and 3.83 ha with standard deviations 1.03, 1.31 and 2.20 respectively. The mean difference in size of farmland holding among the highly vulnerable, moderately vulnerable and less vulnerable groups is statistically significant at $1 \%$ probability level. The mean frequency of farm household heads' contact with extension agents in highly vulnerable, moderately vulnerable and less vulnerable are 1.31, 1.99 and 4.09 times with standard deviations 1.50, 1.64 and 1.54 respectively. The mean difference in frequency of farm household heads' contacts with extension agents among the highly vulnerable, moderately vulnerable and less vulnerable groups is statistically significant at $1 \%$ probability level.

Table 3. Descriptive statistics of continuous variables by perceived vulnerability

\begin{tabular}{llllll}
\hline Variables & $\begin{array}{l}\text { Highly vulnerable } \\
(\mathrm{n}=51)\end{array}$ & $\begin{array}{l}\text { Moderately } \\
\text { vulnerable }(\mathrm{n}=289\end{array}$ & $\begin{array}{l}\text { Less vulnerable } \\
(\mathrm{n}=53)\end{array}$ & $\begin{array}{l}\text { Total } \\
(\mathrm{n}=393)\end{array}$ & $\boldsymbol{F}$ - vlaue \\
\hline Farming experience & $22.08(10.65)$ & $23.59(9.80)$ & $26.17(10.23)$ & $23.74(10.01)$ & 2.31 \\
Education level & $1.22(2.29)$ & $3.12(3.62)$ & $5.72(3.84)$ & $3.23(3.69)$ & $21.81^{* * *}$ \\
Household size & $6.84(2.85)$ & $6.82(2.51)$ & $7.42(2.90)$ & $6.90(2.61)$ & 1.18 \\
Livestock owned & $4.28(2.02)$ & $7.09(2.25)$ & $10.86(3.21)$ & $7.24(2.92)$ & $101.77_{* * *}$ \\
Farm size & $1.04(1.03)$ & $1.95(1.31)$ & $3.83(2.20)$ & $2.09(1.61)$ & $54.57 * * *$ \\
Extension contact & $1.31(1.50)$ & $1.99(1.64)$ & $4.09(1.54)$ & $2.19(1.79)$ & $47.07 * * *$ \\
\hline
\end{tabular}

Note: numbers in parenthesis are percentage, $* * *$ refers significant at $1 \%$

Source: Own survey data, 2018/19

\subsection{Farm Households' Perceived Vulnerability}

The results of both qualitative and quantitative studies depicted that smallholder farmers of the study area have been experiencing a high variability in crop farm income with diminishing trends. This implies the well-being of farm households would be at stake. Results of the perceived vulnerability measurement model using the PCA methodology revealed that 6 items of exposure factors, 5 items of sensitivity factors and 5 items of adaptive capacity factors were perceived as the major components of farm households' vulnerability. Items with factor loading greater than 3.5 were considered as the major components of perceived vulnerability. Moreover, the measurement model explain 92.12 percent of the total variations in the dataset, which is above the threshold.

As reported in Table 4, results of the measurement model shows that climate variability, degradation of farmland fertility, low access to improved inputs, incidence of diseases and pests, too narrow farm margin, and seasonal farm labor deficit were perceived as the major components of exposure factors. Variability in timing and distribution of rainfall and high wave of heat will disrupt the optimum yielding ability of crops and then crop farm income. Infertile farmlands cannot meet the nutrient demand of crops and lead to low yield and low crop farm income. Because of limited supply and high price, smallholder's capacity to afford the use of improved inputs will determine the access of improved inputs. Low access to improved inputs implies the use of traditional low yielding inputs, which leads to low crop yield and low crop farm income. The incidence of diseases and pests will deter the yielding potential of crops and then crop farm income. Because of market price instability (soar price of input market and inhibiting price of output market at the peak season), the farm margin becomes too narrow and low net crop farm income. The seasonality of crop farming activities induces the peak seasonal demands of labor and failure to meet this labor demand leads to lower yield and income. In general, crop farm livelihoods exposures to these multitudes sources of risks induced the likelihood of high variability in crop farm income and the likelihood of smallholder farmers to face livelihood insecurity.

Moreover, the PCA result shows that the limited size of farmland, exhaustive farming, subsistence farming, conservative farming, lack of responsive institutions are the major constituents of susceptibility factors. In the face of a high growth rate in population in general and large size of farm households in particular, operating on a limited size of farmland posit pressure on the biophysical productivity of the farming environment. Hence, the likelihood of crop farming livelihoods indeed in high variability in income is high. An exhaustive farming system without contingency in the face of dynamic landscape induced the likelihood of harvest failure and/or high variability in farm income. The likelihood to face decline in well-being is high in subsistence farming because of that subsistence farming is susceptible to high variability in income. In the face of a dynamic crop farming environment, conservative farming system induces high variability in farm income if conservativeness break sustainability in productivities. Lack of responsive institutions induces the likelihood of high variability in income if intentional responsive institutions provide smallholders with skills, knowledge, and early warning 
information. In general, these sensitivity factors represent the likelihood of high variability in income and livelihood insecurity in the face of exposure factors.

Table 4. Results of the farm households' perceived vulnerability measurement model

\begin{tabular}{lll}
\hline Vulnerability indicators & Factors loading weight & Factors loading scores of PCA1 \\
\hline Exposure factors & & \\
Climate Variability & 0.3965 & 0.3965 \\
Farmland fertility declining & 0.4120 & 0.4120 \\
Low access to improved inputs & 0.4112 & 0.4112 \\
The outbreak of diseases and pests & 0.4041 & 0.4041 \\
Too narrow farm margin & 0.4102 & 0.4102 \\
Seasonal farm labors deficit & 0.4145 & 0.4146 \\
Sensitivity factors & & \\
The limited size of farmland & 0.4144 & -0.0048 \\
Exhaustive farming system & 0.3975 & -0.0049 \\
Subsistence farming & 0.4176 & -0.0061 \\
Conservative production method & 0.4076 & -0.0050 \\
Lack of responsive institutional framework & 0.9383 & 0.0207 \\
Adaptive capacity factors & & \\
Ability to anticipate risky events & 0.4489 & 0.0005 \\
Adequate annual farm income & 0.4574 & 0.0008 \\
Adequate farm reservoir & 0.4547 & 0.0006 \\
Access to off-farm employment & 0.4157 & 0.0009 \\
Access to external financial sources & 0.4572 & -0.0031 \\
\hline
\end{tabular}

Source: Own survey data, 2018/19

Ability to anticipate risky events, adequate annual farm income, adequate farm reservoir, off-farm income, and external financial support are the major constituents of responsive capacities. Smallholders those able to anticipate risky events could reduce the likelihood of high variability in income. Farm households who earn adequate annual farm income could prevent the negative impacts of high variability income and reduce the likelihood to face a decline in well-being. Households with adequate farm reservoir able to cope with high variability in income without eroding the productive farm asset. Households with external financial sources able to recover from the below threshold well-being easily. Smallholders with access to off-farm income opportunities could complement the high variability in income and reduce the likelihood to face a decline in well-being. In general, these adaptive capacity factors represent the capacity to avoid, prevent, or cope up the likelihood of livelihood insecurity.

Moreover, results of the perceived vulnerability measurement model using the first factor leading score of the PCA methodology shows that the computed composite index of the farm households' perceived vulnerability is ranged in -4.567 to 4.644 with a mean $-6.53 \mathrm{E}^{-09}$ and a standard deviation 2.323 . Furthermore, the individual farm household's perceived vulnerability level were predicted using the mean $+/$ - standard deviation of the composite index. As a result farm households with composite index ranged below -2.32 are classified as highly vulnerable, between -2.32 and 2.32 are classified as moderately vulnerable, and ranged above 2.32 are classified as less vulnerable. As reported in Table 6,12.98 percent of the sampled households are highly vulnerable, 73.54 percent are moderately vulnerable and 13.49 percent are less vulnerable while the largest proportion of them (73.54\%) are moderately vulnerable.

\subsection{Determinants of Farm Households' Perceived Vulnerability}

As reported in Table 5, the econometric analysis result shows farming experience, education level, number of livestock, size of farmland, length of the lean season, diversified income sources, credit services, small scale irrigation, off-farm employment opportunities, extension services, and reciprocity of social networking are significantly determined the perceived vulnerability level of farming households.

As reported in the result, farm experience has a negative significant impact on the household's perceived vulnerability level. Gutu et al. (2012), Israel and Belay (2019) and Oni (2008) have also reported the negative relation between farming experience and vulnerability under their cases. This might be because of that farming experiences provided smallholder farmers with accumulated experiential knowledge to manage vulnerable 
conditions.

Table 5. Results of the determinants of farm households' perceived vulnerability model

\begin{tabular}{lllll}
\hline Variables & \multicolumn{4}{l}{ Marginal Effects } \\
\cline { 2 - 5 } & Coefficient & $\mathrm{dy} / \mathrm{dx} 1$ & $\mathrm{dy} / \mathrm{dx} 2$ & $\mathrm{dy} / \mathrm{dx} 3$ \\
\hline Sex & $0.339(0.351)$ & -0.0232 & 0.0114 & 0.0118 \\
Farming experience & $0.029(0.008)^{* *}$ & -0.0015 & 0.0001 & 0.0014 \\
Household size & $-0.038(0.033)$ & 0.0019 & -0.0002 & -0.0017 \\
Education level & $0.107(0.028)^{* *}$ & -0.0055 & 0.0005 & 0.0050 \\
Livestock owned & $0.038(0.023)^{*}$ & -0.0019 & 0.0002 & 0.0018 \\
Farm size & $0.264(0.066)^{* * *}$ & -0.0136 & 0.0012 & 0.0124 \\
On-farm diversification & $0.872(0.191)^{* * *}$ & -0.0390 & -0.0171 & 0.0561 \\
Access to credit & $0.792(0.252)^{* *}$ & -0.0252 & -0.0411 & 0.0663 \\
Small scale irrigation & $0.688(0.268)^{* *}$ & -0.0210 & -0.0364 & 0.0574 \\
Off-farming income & $0.523(0.174)^{* *}$ & -0.0243 & 0.0046 & 0.0289 \\
Extension contact & $0.288(0.058)^{* * *}$ & -0.0148 & 0.0013 & 0.0135 \\
Social capital & $0.987(0.223)^{* * *}$ & -0.1057 & 0.0812 & 0.0245 \\
\hline
\end{tabular}

Note: $* * *, * *$, and $*$ refers significant at $1 \%, 5 \%$ and $10 \%$

Source: Own survey data, 2018/19

The education level of farm household head also has a negative significant impact on the household's perceived vulnerability level. Yitayal and Adam (2017) and Zenebe et al. (2016) also reported that education is the key factor in building responsive capacities. This might be because of that educated farm households are in a better position to manage vulnerable conditions. Moreover, the number of livestock and the size of farmland owned have a significant negative impact on the household's perceived vulnerability level. Gutu et al., 2012; Israel and Belay, 2019 also found a negative relation between household asset and vulnerability. Households operating on large farmland and/or owning large number of livestock can resist or absorb or cope up the livelihood insecurity induced by (a)biotic risks.

Smallholder farmers' access to diversified sources of farm income has a significant negative impact on the perceived vulnerability level. Glwadys et al. (2010); Opiyo et al. (2014); Pandey et al. (2017) and Tessema and Simane (2019) also found that income diversification minimizes the likelihood to be in high vulnerable conditions. This might be because of that income diversification provide opportunities for spreading the adverse impacts across different livelihood strategies and enhance responsive capacities for absorbing and/or shielding from the negative impacts of risks. In the same vein, access to credit service has significant negative impacts on the perceived vulnerability level. Pandey et al. (2017) also reported that households with access to credit service are less vulnerable. This might be because of that access to affordable credit can avoid selling or renting productive farm resources during the lean season and enable to build responsive capacities.

Smallholder farmers' access to small-scale irrigation has significant negative impacts on the perceived vulnerability level. Afroz and Akhtar (2017); Fang et al. (2016), and Gbetibouo et al. (2010) have reported the negative relation between access to small-scale irrigation and farmers' vulnerability. Access to small-scale irrigation could enable smallholder farmers to manage variability in timing, intensity, and amount of rainfall on the one hand and open an opportunity to earn off-season income from cash crops using irrigation on the other hand. Similarly, smallholder farmers' access to non-farming income opportunities has significant negative impacts on the perceived vulnerability level. Yitayal and Adam (2017) also reported the significant role of off-farm employment opportunities in the management of livelihood insecurity in the central Rift Valley of Ethiopia. In the limited insurance and credit market as well as precautionary saving, off-farm income opportunities can play a significant role in building responsive capacities of smallholder farmers.

Smallholder farmers' access to extension service has a significant negative impact on the perceived vulnerability level. Lockwood et al. (2015), Opiyo et al. (2014), Pandey et al. (2017), and Rossi et al. (2012) have also reported the positive role of extension service to enhance the technical skill of farmers. This might be because of that extension workers are expected to provide consultancy and advisory services to enhance information access and technical skills of smallholder farmers, which improve their responsive capacities. In the same vein, smallholder farmers' trust in the reciprocity of local networks has a significant negative impact on the perceived vulnerability level. Opiyo et al. (2014), Pandey et al. (2017), and Tessema and Simane (2019) found that social 
capital improves the responsive capacity of farmers under their cases. Peer networks provide practical support in information and resource sharing among farming communities. Moreover, reciprocity in local networks provides strong bonds within social groups and outside groups that can bring in additional social, financial, and political resources and enhance farmers' responsive capacities.

\section{Conclusions and Recommendations}

Smallholder farmers of the study area are exposed to climate variability, farmland fertility declining, low access to improved inputs, outbreaks of diseases and pests, too narrow farm margin, and seasonal farm operator deficit. In the same vein, they are sensitive to the adverse impacts of these exposure factors because of operating on the infertile limited size of farmland, employed exhaustive farming, engaged in subsistence farming, adapted conservative farming, and lack of responsive institution in the face of harm. Similarly, because of their inability to anticipate risky events, lack of adequate annual farm income, lack of adequate farm reservoir, lack of off-farm income, and lack of external financial support, their responsive capacities were constrained. Hence, they are forced to bear all the adverse impacts posed by the vulnerability components of the farming system.

About 12.98 percent of the sampled farm households require permanent external support while 73.54 percent of them require temporary external support to recover after the crop farm income shocks. In the same vein, 77 percent of the highly vulnerable groups faced more than 3 months of lean season and 72 percent of the less vulnerable groups faced less than 3 months of lean season. Besides, it was reported that farming experience, education level, livestock owned, farm size, on-farm diversification, access to credit, small scale irrigation, off-farming income, extension contact, and social capital are significantly affecting the perceived vulnerability level with the differential magnitude and direction of impact.

In general, the findings of this study showed that the livelihoods of smallholder farmers in the study area are vulnerable because of a multitude risks and constrained responsive capacities. Subsistence farming and absence of market-based risk management strategies aggravate the level of farm households' livelihood insecurity. These calls for government or non-government interventions for minimizing the likelihood of exposure and sensitivities; and enhancing responsive capacities through need-based intervention plans focusing on improving rural infrastructure and facilities that provide income diversification and off-farm employment opportunities; improving access to small-scale irrigation and affordable credit services; and building the capacity of extension workers to improve extension services. Such interventions could enhance the responsive capacities of smallholder farmers in the short-run and minimize the likelihood of exposure and sensitivity in the long-run. Moreover, effective and responsive risk governance structures and flexible institutional setup also called to support smallholder farmers of the study area.

\section{Acknowledgement}

Ethiopian Ministry of Science and Higher Education (MOSHE) for providing an opportunity for this study. Grateful acknowledgement also Ambo University and Haramaya University for facilitating the necessary conditions during this study.

\section{Author Declaration}

Funding: Ethiopia Ministry of Science and Higher Education (MOSHE) through Ambo University has financed this study.

Availability of data and material: upon request, the corresponding author can supply data in the format wanted.

Authors' contribution: All authors actively involved in designing the research tools, analysis, and write up of this manuscript. Moreover, the manuscript has been read and approved by all authors.

Competing interests: The authors have declared that they have no competing interests.

\section{Reference}

Adger, N. W. (1995). Approaches to Vulnerability to Climate Change (CSERGE Working Paper GEC 96-05).

Adger, W. N. (2006). Vulnerability. Global Environmental Change, 16(1), 268-281. https://doi.org/10.1016/j.gloenvcha.2006.02.006

Asravor, R. K. (2019). Farmers' Risk Preference and the Adoption of Risk Management Strategies in Northern Ghana. Journal of Environmental Planning and Management, 62(5), 881-900. https://doi.org/10.1080/09640568.2018.1452724

Bard, S. K., \& Barry, P. J. (2001). Assessing Farmers' Attitudes Toward Risk Using the "Closing-in” Method. 
Journal of Agricultural and Resource Economics, 26(1), 248-260. https://doi.org/10.2307/40987106

Belaineh, L., \& Drake, L. (2005). Determinants of Smallholder Farmers' Perceptions of Risk in the Eastern Highlands of Ethiopia. Journal of Risk Research, 8(5), 383-416. https://doi.org/10.1080/1366987042000192426

Bezuayehu, T., Gezahegn, A., Yigezu, A., Jabbar, M. A., \& Paulos, D. (2002). Nature and Causes of Land Degradation in the Oromiya Region: A review. Issue Socio-economics and Policy Research Working Paper 36.

Birkmann, J., Cardona, O. D., Carreño, M. L., Barbat, A. H., Pelling, M., Schneiderbauer, S., ... Welle, T. (2013). Framing Vulnerability, Risk and Societal Responses: The MOVE Framework. Natural Hazards, 67(2), 193-211. https://doi.org/10.1007/s11069-013-0558-5

Brien, K. O., Eriksen, S., Schjolden, A., \& Nygaard, L. (2004). What's in a Word? Conflicting Interpretations of Vulnerability in Climate Change Research. No. 04; CICERO Working Paper 2004.

Christiaensen, L. J., \& Subbarao, K. (2004). Toward an Understanding of Household Vulnerability in Rural Kenya. World Bank Policy Research Working Paper 3326. pp. 1-44.

Dubale, P. (2001). Soil and Water Resources and Degradation Factors Affecting Productivity in Ethiopian Highland Agro-ecosystems. Northeast African Studies, New Series, 8(1), 27-51. https://doi.org/10.1353/nas.2005.0015

Duong, T. T., Brewer, T., Luck, J., \& Zander, K. (2019). A Global Review of Farmers' Perceptions of Agricultural Risks and Risk Management Strategies. Journal of Agriculture, 9(1).

https://doi.org/10.3390/agriculture9010010

Eitzinger, A., Binder, C. R., \& Meyer, M. A. (2018). Risk Perception and Decision-Making: Do Farmers Consider Risks From Climate Change? Journal of Climate Change, 151(1), 507-524. https://doi.org/10.1007/s10584-018-2320-1

Fang, Y. P., Zhao, C., Rasul, G., \& Wahid, S. M. (2016). Rural Household Vulnerability and Strategies for Improvement: An Empirical Analysis Based on Time Series. Habitat International, 53(2016), 254-264. https://doi.org/10.1016/j.habitatint.2015.11.035

Feola, G., \& Binder, C. R. (2010). Towards an Improved Understanding of Farmers' Behaviour: The Integrative Agent-Centred (IAC) Framework. Jounal of Ecological Economics, 69(12), 2323-2333. https://doi.org/10.1016/j.ecolecon.2010.07.023

Feola, G., Lerner, A. M., Jain, M., Montefrio, J. F. M., \& Nicholas, K. A. (2015). Researching Farmer Behaviour in Climate Change Adaptation and Sustainable Agriculture: Lessons Learned from Five Case Studies. Journal of Rural Studies, 39(1), 74-84. https://doi.org/10.1016/j.jrurstud.2015.03.009

Gbetibouo, A. G., \& Ringler, C. (2009). Mapping South African Farming Sector Vulnerability to Climate Change and Variability: A Subnational Assessment. FPRI Discussion Paper Series, 00885, 1-27. https://doi.org/10.1006/jesp.1999.1398

Gbetibouo, G. A., Ringler, C., \& Hassan, R. (2010). Vulnerability of the South African farming sector to climate change and variability : An indicator approach. Natural Resources Forum, 34(2010), 175-187. https://doi.org/10.1111/j.1477-8947.2010.01302.x

Gebreegziabher, Z., Mekonnen, A., Deribe, R., Boka, J., \& Abera, S. (2016). Mapping Vulnerability to Climate Change of the Farming Sector in the Nile Basin of Ethiopia: A Micro-level Perspective. Environment for Development Discussion Paper Series 16-19.

Ginkel, van M., Sayer, J., Sinclair, F., Aw-Hassan, A., Bossio, D., Craufurd, P., ... Ortiz, R. (2013). An Integrated Agro-Ecosystem and Livelihood Systems Approach for the Poor and Vulnerable in Dry Areas. Food Security, 5(6), 751-767. https://doi.org/10.1007/s12571-013-0305-5

Gutu, T., Bezabih, E., \& Mengistu, K. (2012). Analysis of Vulnerability and Resilience to Climate Change Induced Shocks in North Shewa, Ethiopia. Agricultural Sciences, 03(06), 871-888. https://doi.org/10.4236/as.2012.36106

Hahn, M. B., Riederer, A. M., \& Foster, S. O. (2009). The Livelihood Vulnerability Index: A pragmatic Approach to Assessing Risks From Climate Variability and Change, A case Study in Mozambique. Global Environmetal Change, 19, 74-88. https://doi.org/10.1016/j.gloenvcha.2008.11.002 
Harvey, C. A., Rakotobe, Z. L., Rao, N. S., Dave, R., Razafimahatratra, H., Rabarijohn, R. H., Rajaofara, H., \& MacKinnon, J. L. (2014). Extreme vulnerability of smallholder farmers to agricultural risks and climate change in Madagascar. Philosophical Transactions of the Royal Society B: Biological Sciences, 369(1639). https://doi.org/10.1098/rstb.2013.0089

Harwood, J., Richard, H., Coble, K., Perry, J., \& Somwaru, A. (1999). Managing Risk in Farming: Concepts, Research, and Analysis. Agricultural Economic Report, 774, 125. Retrieved from https://ageconsearch.umn.edu/bitstream/34081/1/ae990774.pdf

Helamo, E. M. (2018). Review on Smallholders Farm Risk and Management Strategies in Ethiopia. Journal of Poverty, Investment and Development, 44(1), 24-31.

Israel, T., \& Belay, S. (2019). Vulnerability Analysis of Smallholder Farmers to Climate Variability and Change: An Agro-Ecological System-Based Approach in the Fincha'a Sub-Basin of the Upper Blue Nile Basin of Ethiopia. Ecological Processes, 8(1). https://doi.org/10.1186/s13717-019-0159-7

Jamshidi, O., Asadi, A., Kalantari, K., Azadi, H., \& Sche, J. (2019). Vulnerability to climate change of smallholder farmers in the Hamadan province, Iran. Climate Risk Management, 23(2019), 149-159. https://doi.org/10.1016/j.crm.2018.06.002

Kahan, D. (2008). Managing Risk in Farming. Food and Agriculture Organization of the United Nations (FAO).

Larcher, M., Sch, M., \& Schmid, E. (2016). Risk Perception and Assessment in Austrian Agriculture and Forestry. Journal of the Austrian Society of Agricultural Economics, 25(1), 221-230.

Moschini, G., \& Hennessy, D. (1999). Uncertainty, Risk Aversion and Risk Management for Agricultural Producers. Economic Staff Paper Series 315.

Murphy, D. J., Myborn, C., Yung, L., \& Williams, D. R. (2015). Key Concepts and Methods in Social Vulnerability and Adaptive Capacity. General Technical Report RMRS-GTR-328. https://doi.org/10.2737/RMRS-GTR-328

Olusola, A. (2014). Climate Change Effects on Household Agric-Economy and Adaptive Responses among Agricultural Households in Nigeria. Famine Early Warning Systems Network, 1-18.

Oni, O. A. (2008). Farming Households' Vulnerability to Risk in the Northern Region of Oyo State, Nigeria. Journal of Social Sciences, 17(3), 201-210. https://doi.org/10.1080/09718923.2008.11892652

Opiyo, F. E. O., Wasonga, O. V., \& Nyangito, M. M. (2014). Measuring Household Vulnerability to Climate-Induced Stresses in Pastoral Rangelands of Kenya: Implications for Resilience Programming. Pastoralism: Research, Policy and Practice, 4(1), 1-15. https://doi.org/10.1186/s13570-014-0010-9

Pandey, R., Jha, S. K., Alatalo, J. M., Archie, K. M., \& Gupta, A. K. (2017). Sustainable Livelihood Framework-Based Indicators for Assessing Climate Change Vulnerability and Adaptation for Himalayan Communities. Ecological Indicators, 79, 338-346. https://doi.org/10.1016/j.ecolind.2017.03.047

Paulos, A., \& Belay, S. (2018). Farmers' Perception of Climate Change and Adaptation Strategies in the Dabus Watershed, North-West Ethiopia. Journal of Ecological Process, 7(7), 1-13. https://doi.org/10.1186/s13717-018-0118-8

Roxana, L. C., Dagmar, S., \& Thomas, G. (2012). Conceptual Frameworks of Vulnerability Assessments for Natural Disasters Reduction. In C. Et (Ed.), Approaches to Disaster Management - Examining the Implications of Hazards, Emergencies and Disasters (p. 38). INTECH. https://doi.org/10.1016/j.colsurfa.2011.12.014

Saguye, T. S. (2017). Analysis of Farmers' Perception on the Impact of Land Degradation Hazard on Agricultural Land Productivity in Jeldu District in West Shewa Zone, Oromia, Ethiopia. Journal of Agricultural Extension and Rural Development, 9(6), 111-123. https://doi.org/10.5897/JAERD2017.0854

Sattar, R. S., Wang, S., Tahir, M. N., \& Caldwell, C. (2017). Assessment of Smallholder Farmer's Vulnerability Due to Climate Change in Arid Areas of Pakistan. Applied Ecology and Environmental Research, 15(4), 291-312. https://doi.org/10.15666/aeer/1504_291312

Shikuku, K. M., Winowiecki, L., Twyman, J., Eitzinger, A., Perez, J. G., Mwongera, C., \& Läderach, P. (2017). Smallholder Farmers' Attitudes and Determinants of Adaptation to Climate Risks in East Africa. Climate Risk Management, 16(1), 234-245. https://doi.org/10.1016/j.crm.2017.03.001

Singh, J. (2018). Managing Risk and Uncertainty in Indian Agriculture. Upuea Ecnonomic Journal, 14(1), 44-47. 
www.nabard.org

Singh, N. P., Anand, B., \& Khan, A. M. (2018). Micro-Level Perception to Climate Change and Adaptation Issues: A Prelude to Mainstreaming Climate Adaptation into Developmental Landscape in India. Jornal of Natural Hazards, 92(1), 1287-1304. https://doi.org/10.1007/s11069-018-3250-y

Singh, P. K., \& Nair, A. (2014). Livelihood Vulnerability Assessment to Climate Variability and Change Using Fuzzy Cognitive Mapping Approach. Climate Change, 127, 475-491. https://doi.org/10.1007/s10584-014-1275-0

Tefera, B., Ayele, G., Atnafe, Y., Jabbar, M. A., Dubale, P., Jabbar, M. A., Ehui, S. K., \& Staal, S. J. (2002). Nature and causes of land degradation in the Oromiya Region: A review Socio-economics and Policy Research Working Paper 36. Socio-Economics and Policy Research Working Paper 36.

The World Bank. (2013). World Development Report 2014 - Risk and Opportunity: Managing Risk for Development.

Walker, B., Gunderson, L. H., Kinzig, A., Folke, C., Carpenter, S., \& Schultz, L. (2006). A Handful of Heuristics and Some Propositions for Understanding Resilience. Journal of Ecology and Society, 11(1), 13. https://doi.org/10.5751/ES-01530-110113

Wallace, M. T., \& Moss, J. E. (2002). Farmer Decision-making with Conflicting Goals: A Recursive Strategic Programming Analysis. Journal of Agricultural Economics, 53(1), 82-100.

https://doi.org/10.1111/j.1477-9552.2002.tb00007.x

Williams, P. A., Crespo, O., Abu, M., \& Simpson, N. P. (2018). A systematic review of how vulnerability of smallholder agricultural systems to changing climate is assessed in Africa. Environmental Research Letters, 13(10). https://doi.org/10.1088/1748-9326/aae026

Yitayal, A., \& Adam, B. (2017). Vulnerability of Smallholder Farmers to Climate Change in the Central Rift Valley of Ethiopia : A Gender Disaggregated Approach. Ehiop. J. Agric. Sci., 27(2), 85-97.

Zarafshani, K., Shara, L., Azadi, H., Hosseininia, G., Maeyer, P. De, \& Witlox, F. (2012). Drought Vulnerability Assessment: The Case of Wheat Farmers in Western Iran. Global and Planetary Change, 99, 122-130. https://doi.org/10.1016/j.gloplacha.2012.08.012

Zenebe, G., Alemu, M., Rahel, D., Jonse, B., \& Samuel, A. (2016). Mapping Vulnerability to Climate Change of the Farming Sector in the Nile Basin of Ethiopia, A Micro-level Perspective. In Environment for Development.

\section{Copyrights}

Copyright for this article is retained by the author(s), with first publication rights granted to the journal.

This is an open-access article distributed under the terms and conditions of the Creative Commons Attribution license (http://creativecommons.org/licenses/by/3.0/). 